\title{
Parent-Adolescent Relationship With Respect to Parental Acceptance- Rejection among Students in Secondary Schools
}

\author{
Haslee Sharil Lim \\ Abdullah $^{1}$
}

\author{
Poh Li, $\mathrm{Lau}^{2}$ \\ Department of Educational \\ Psychology and \\ Counseling, University of \\ Malaya, Malaysia $a^{1,2,3}$
}

\author{
Lih Peng, $\mathrm{Ooi}^{3}$
}

\begin{abstract}
This study aimed at providing the relevant information pertaining to the general overall picture of parent-adolescent relationship with respect to parental acceptance- rejection and to determine whether demographic variables affect the parent-adolescent relationship with respect to parental acceptancerejection significantly. The sample comprised 321 male and female Form Four students (grades 11) from two schools in Selangor, Malaysia. The instruments used were Research Sample Demography Data Information and the Parental Acceptance-Rejection Questionnaire (PARQ). As a result, the comparison of the PAR score between the ethnic groups revealed significant differences for the father-adolescent and motheradolescent relationship between ethnic groups, $F$ (3, $317)=5.53, p=.00$ and $F(3,317)=4.58, p=.00$ respectively. Further, the comparison of PAR score between academic achievement levels also show significant differences for father-adolescent and mother-adolescent relationship across students with different academic achievement, $F(3,317)=4.62, p$ $=.00$ and $F(3,317)=6.99, p=.00$. There was no significant difference for the effects of other demographic variables namely gender, parents' education qualification, parents' working status and monthly total household incomes on parent-adolescent relationship with respect to parental acceptancerejection. This information on students' perception of father and mother is useful to parents, educationists, principals, teachers and counselors who wish to improve the parent-adolescent relationship in order to maximize adolescent well-being and in developing more effective and productive parents.
\end{abstract}

\section{Introduction}

According to Nielsen [1], adolescence is known as a period of life that is somehow distinct from both childhood and adulthood. According to Papalia [2], throughout the human life span development, adolescence is a stage when individuals are leaving their childhood and entering into a preparation stage for attaining adulthood to assume higher responsibilities independently in the future. Adolescence is a complex process of growth and change. This is due to changes in bodily growth in terms of both physical and physiological, cognitive development and psychosocial relationship among family members and peer groups at this stage of life. Adolescence is an intriguing stage of development filled with many physical, cognitive, social and emotional changes in attaining a unique self and a mentally healthy social being within society contexts.

In the 21st century, the task of helping students to be successful and contributing members of society has become more challenging than ever. Today's adolescents are confronted with a rapidly changing work world and labor force, violence in homes, schools and communities, divorce, teenage suicide, substance abuse, and sexual experimentation. These complex challenges will have a significant impact on the academic, career, personal and social development of students. The increasing academic demands and the complexity of the school structure complicate academic success for adolescents.

This is supported by Grinder [3], who stated that adolescents face many challenges during the growing up process.

Developmental failure and stress have been viewed to originate from home. The conflict between parents and adolescents centers upon several recurring issues in the lives of adolescents. Furthermore, Rohaty Mohd. Majzub [4] has commented that the parent-adolescent relationship is often thought to be one of conflict and tension. 
Regardless of age, children need parents. Indeed, across multiple studies, research appears to show that the quality of the parent-teen relationships is linked to a wide range of positive outcomes, such as social competence and interaction, emotional well-being and being well-adjusted with a corresponding decrease in problematic behavior such as substance abuse, delinquency and sexual activity and is also related to positive teen behaviors and academic outcomes. Therefore, parental involvement has been shown to be a very important positive force in a child's life.

Glasser [5] pointed out that the major human problems are violence, crime, child abuse, spousal abuse, alcohol and drug addiction, and the proliferation of premature and unloving sex and emotional distress caused by unsatisfying relationships. The rising incidences among adolescents' truancy, rebellious behaviour, such as running away from home, injuring or killing peers while fighting over material items and school indiscipline problems obviously need to be addressed. Therefore, we need to focus on the parentadolescent relationship in order to form a strong foundation of communication between them. Furthermore, adolescents especially need good parentchild and teacher-student relationships if they are to avoid self-destructive behaviours [5].

Dacey and Kenny [6] pointed put that the five major functions of family - economics-productive, educational, religious, recreational and medical have been taken out of the home environment to other respective institutions away from home. The newer family functions are closely connected with the provision of affection, support and nurturance to family members. Feelings of affection among family members are generated through their daily relationships, which are built up from the interactions that take place as a whole in the family unit.

Despite recent controversy over the role and importance of parents, considerable research indicates that the parent-child relationship is important in the life of infants, children, young adolescents and teens. Regardless of age, children need parents. As for the majority of adolescents, parents remain an important source of social capital. Historically across diverse cultures, parents have been identified as central influences in child development. Reviewing across multiple studies, research shows that quality of parentteen relationships is linked to a wide range of positive outcomes such as social competence and interaction, emotional well-being, well-adjusted with a corresponding decrease in problematic behavior like substance abuse, delinquency, and sexual activity as well as related to positive teen behaviors and outcomes in academic settings.

Chiam [7] emphasized that adolescents encounter adjustment problems. Whether they have the ability or disability to make adjustments will enable these adolescents to become psychologically integrated and effective members or a liability to society. The extent of their adjustments depends upon the people in their environment, especially the significant others, who can either facilitate or hinder their transition to adulthood by helping adolescent to understand themselves better.

According to Trojanowicz and Morash [8], while most parents do realize and are aware of the high increase in the number of delinquent behavior cases, they usually think that such unfortunate incidences only happen to others. Normal reactions of parents are to blame such delinquent behaviors on the inadequate education system, the adolescents themselves, peer influence or uncontrollable environment factors as the main cause. As a result, parents have neglected to do a post mortem on themselves as the initial and main persons in providing the nurturing and affectionate roles to build a strong foundation of attachment relationship with children since young.

Keefauver [9] says that changes in the family and their effects on family life can be seen in recent decades whereby more time is being taken up by work and school, and family members seem to have less time to spend together. With the rapid progress in economic, cultural and technological fields, families are further being threatened by exposure to telecommunications, satellite communications and advancements of the information age. Television, music, videos, fantasy games, video games, and the internet are poor substitutes for forging friendships and sharing among adolescents. If an adolescent spends more hours a day relating to virtual reality rather than the reality of family, then the dangerous wall of misbehaviour is being built. When we neglect our relationships with adolescents, especially by failing to talk together often, then all kinds of tempting, suspicious thoughts can arise in both parties. The only way for both parties to be together in a parentadolescent relationship is to continually talk with one another as friends [9]. Otherwise, feelings of neglect or rejection can invade the parent-adolescent relationship, causing offense, suspicion and a wall of mistrust.

\section{Significance of Study}

This study is a time resolved study and is hoped to gain a general level of understanding of the critical and important function of eliminating delinquent behaviour among adolescents. In parents, for identifying the root to solving delinquent behavior, it also indirectly reveals the need for parents to be exposed to learning opportunities such as attending seminars and short courses to learn to be effective and efficient parents and to ensure operation of a fully functional family system. 
It is hoped that this study will provide the relevant information pertaining to the general overall picture of parent-adolescent communication and parentadolescent relationship with respect to parental acceptance-rejection to the parents, school counsellors, teachers family and marriage counsellors, District and State Education Department, Women, Family and Community Development Ministry, non-governmental organizations and other social service bodies within the nation. With this knowledge and understanding, it is believed that the various parties will take the initiative to work together as inter or intra departments in order to plan preventive and interventional programs to deal directly with the problems facing Malaysian parents and adolescents. It is encouraged that multiple programs targeting in connecting parents and adolescents are necessary in further education through improvised strategy, seminars, workshops or programs for adolescents, parents and family overall in connecting and enhancing the missing link of a family in whole. Such efforts shall benefit the adolescents' psychological wellness in the long term.

The purpose of this study is also to educate and shape the individuals of a family to be responsible and considerate in order to nurture intimacy to form a loving and harmonious family. This in turn will build a progressive and prosperous society starting from the family.

\section{Parent-adolescent Relationship with regard to Parental Acceptance-Rejection Theory}

Rohner and Rohner [10] note that parental warmth (acceptance-rejection) and parental control (permissiveness-strictness) have been shown to be the two major dimensions of parenting. It has been emphasized over the importance of parental warmth and affection for "normal" personality development. The literature review will cover the cross-cultural evidence for information about the profound effects of parental acceptance-rejection on the personality of children and adults.

All human beings have a profound generalized need for positive response (love, approval, warmth, affection) from the people who are important to us. The bare minimum care that human beings must have for physical survival is not enough for normal psychosocial development. The need for positive response is probably rooted in man's biological and evolutionary development, and is reinforced in the experience of infantile instrumental dependency. The absence or significant withdrawal of warmth and affection is sufficient to produce massive and predictable consequences for personality functioning. Rejection inhibits or distorts aspects of normal personality functioning, such as feelings of positive self-esteem and self-adequacy. All of us tend to view ourselves as we imagine significant others view us, and if parents rejected us as children, we are likely to define ourselves as unworthy of love and therefore as unworthy and inadequate human beings. In this way, we develop a sense of overall negative self-evaluation.

The kind of love parents can give or withhold from their children along with the consequences of parental love, warmth, and affection (i.e., acceptance) are profound and generally productive of positive social and emotional health. Rejection is a form of parental behavior characterized by the absence or withdrawal of warmth and affection. Rejecting parents often dislike, disapprove of, or resent their children. However, greater emphasis places on the absence of significant withdrawal of parental love (i.e., rejection), because its effects are more immediately and conspicuously apparent than the effects of parental acceptance. The withdrawal or absence of love by itself seems to be sufficient to produce stark and often profoundly damaging consequences for growing children as well as for adults who were rejected as children.

Rohner [11] discussed a constellation of personality traits that seem to characterize rejected children the world over. These traits include hostility, aggression, passive aggression, or problems with managing hostility and aggression, negative self-evaluation, dependence, emotional unresponsiveness, negative worldview, and emotional instability.

In the research on the consequences of rejection, rejected children in comparison with accepted children were reported to be significantly more hostile, aggressive or passive aggressive, tend to devaluate themselves, dislike themselves, were uncomfortable with themselves and perceive themselves as being worthless or worthy of condemnation. The rejected children may have self-dislike generated by the belief that their parents do not love or want them and that they are therefore unworthy of love.

Parental rejection creates anxiety; hence the rejected child tends to be insecure. From this psychologically painful early experience, the rejected child develops a generalized negative world view. Children who have suffered emotional hurt from parents - the most important people from whom they take their earliest cues about the nature of the world are unlikely to develop a sense of trust and confidence in themselves and the world around them [11]. 


\section{Impact of Parental Acceptance- Rejection}

Abdullah Malim Baginda [12] discussed that in general, researchers assumed that delinquent behaviors are not caused by one particular factor but the combination of a few factors in the society that allows the delinquent behavior. Nevertheless, numerous researchers have suggested that family factors, especially the parental aspect, play an important role in determining the development of delinquent behaviors.

Cross [13] also made a remark that the two worlds, school and home, especially influence how adolescents feel about their place in the larger community. Perhaps, due to the stage of adolescents in identity formation, it is important as part of their development that they find meaning in the world they live in. Part of their meaning would relate more with issues such as selfesteem, significance and relationships.

Yap [14] pointed out that studies conducted in the Western context show the factor of parental involvement in preparing a conducive environment, parental interaction and direct parental involvement in their children's academic development could be helpful for developing cognitive abilities as well as encouraging their affection development.

Rohner and Pettengill [15] say that a major finding on Korean adolescents' perceptions on both their father and mother was that as the overall parental control increased, perceptions of parental warmth increased too. In Korea, parents who are perceived to be strict are also seen as being less neglecting and indifferent than more permissive parents.

In Eskilson, Muehlbauer and Dodder [16] research on the young adolescent sample found that children who experienced excessive pressure to achieve and succeed in school were reported to have lower selfesteem and greater involvement in deviant activity.

Phares and Renk [17] pointed out that the adolescents' reports of parental acceptance were correlated with positive affect and inversely correlated with negative affect for both mothers and fathers. Greater maternal control was associated with higher levels of negative affect, whereas greater paternal control was associated with higher levels of positive affect.

Thus, family plays an important role in the adolescents' life due to its socialization process within a family that can influence adolescents' behavior in society. Socialization process is the process experienced by individuals in learning and internalizing their appropriate behavior, values and attitudes to function as social human beings and responsive individuals participating in a society.

According to Barnes and Farrel [18], family socialization process is the basic for maintaining social rules and to encourage proper behavior. Therefore, fully functional parents who are able to provide full supervision and control of the children are important facts in order to reduce the possibility of their children's inclination toward delinquent behavior.

Shek [19] found that adolescents perceived the mother- adolescent relationship to be more important than the father-adolescent; however adolescent females, as compared with males, were reported as being less satisfied with their communication with parents.

\section{Important Operational Definitions of Terms}

\subsection{Parental Acceptance-Rejection}

Acceptance means favorable reception, approval to receive (something offered), especially with gladness or approval. On the other hand, rejection reflects the act of rejecting or the state of being rejected, to refuse to accept, to refuse to recognize or give affection to a person. Parental acceptance-rejection relates to the parents' action of communication which results in generating the sense of acceptance or rejection in the eyes of the adolescent.

\subsection{Secondary School Student}

The term secondary school student in this study refers to an adolescent aged 16-17 who is currently studying in Form Four in a Malaysian government secondary school. Adolescent refers to an individual who is in the transitional period between childhood and adulthood. The Malaysian government secondary school is a national language, Malay medium school and students are either transferred from Malay, Chinese or Indian language medium primary schools.

\subsection{Ethnic}

American Heritage Dictionary explains ethnic as pertaining to the origin, classification or characteristic of a people or group sharing a common and distinctive culture, religion, language, or the like. Since Malaysia is made up of three main ethnic groups, that is, Malay, Chinese, and Indian, this was one of the criteria that were studied.

\subsection{Academie Achievement}

Kerlinger [19] explained that achievement is the score that was academic achieved in a test or major examination by the student. Academic achievement is determined by the examination result. It is well 
accepted as a measurement of the mental ability and degree of intelligence. Intelligence quotient (IQ) tests are more complex and few people are conducting it. Due to this, examination results are widely used as a prediction of academic achievement. In this study, academic achievement is measured by grades obtained by the students in the Lower Secondary Assessment or “Penilaian Menengah Rendah” (PMR) examination.

\section{Present Study}

The study is geared toward achieving the objectives as stated:

1. To examine the perception among the secondary school students on parent-adolescent relationship with respect to parental acceptancerejection;

2. To determine whether demographic variables affect the parent-adolescent relationship with respect to parental acceptance-rejection.

Based upon the objectives of the study, the following research questions have been formulated:

1. What is the perception among the secondary school students on parent-adolescent relationship with respect to parental acceptance-rejection?

2. Are there any significant differences among the secondary school students' perception on parentadolescent relationship with respect to parental acceptance-rejection based on the following demographic variable:
a) Gender
b) Ethnic groups
c) Academic achievements
d) Parents' education qualifications
e) Parents' working status
f) Monthly total household incomes

\section{Methodology}

A survey research design was employed to examine the presented research questions regarding the parentadolescent relationship with respect to parental acceptance-rejection. This research is quantitative in nature as survey was conducted through the use of questionnaire.

\subsection{Research Design}

This study is a type of survey research done with the intention to determine answers to the presented research questions concerning the current status of Malaysian adolescents. This research is quantitative in nature as survey is conducted through the use of questionnaire. An ex post facto design was used in this study. The type of ex post facto design in this study is the correlational study involving the collection of two or more sets of data from of subjects with the attempt to determine the subsequent relationship between those sets of data [16]. The investigation of parentadolescent relationship with respect to parental acceptance-rejection as perceived by students and the inclusion of both their father and mother with this study would allow for an investigation into the different influencing factors.

\subsection{Location of Study}

The study was school-based which targeted two survey neighborhood government secondary schools. The schools were Sekolah Menengah Kebangsaan Bandar Kinrara Seksyen 1 and Sekolah Menengah Kebangsaan Bandar Kinrara Seksyen 4 situated in Puchong, Selangor, Malaysia. Both of these schools were selected as they consisted of students from different ethnic groups, who were originally from two vernacular schools Sekolah Rendah Kebangsaan. Sekolah Rendah Jenis Kebangsaan (Cina) and Sekolah Rendah Jenis Kebangsaan (Tamil).

Malaysia is a multi-racial society. In order to gain a better understanding of society today, a representative sample was chosen in adolescents on terms of gender and ethnic from coeducational schools with a multiracial population (Malay, Chinese, and Indian) for this study. Furthermore, the distance between both schools is less than $1 \mathrm{~km}$, thus minimizing the impact of environmental factors on the samples. This is appropriate for the purpose of studying how the various ethnic groups' background impact the parentadolescent relationship with respect to parental acceptance-rejection.

\subsection{Research Sample}

Total of 321 Form four male and female students participated in the present study. Out of the 321 students, 124 (38.6\%) were from Sekolah Menengah Kebangsaan Bandar Kinrara Seksyen 1 and 197 (61.4\%) were from Sekolah Menengah Kebangsaan Bandar Kinrara Seksyen 4. Their age ranged from 1617 years old.

These groups of students who have just completed their PMR examination in 2006 were not preparing for any government school major examination when the study was conducted. In terms of gender composition, 158 (49.2\%) participants were males and 163 (50.8\%) were females. As for ethnicity, 94 (29.3\%) were 
Malays, 161 (50.2\%) were Chinese, 55 (17.1\%) were Indian and 11 (3.4\%) were from other ethnic groups.

\subsection{Instruments}

Two major instruments were utilized for the current study, namely:

i. Research sample demography information data.

This instrument was used to gather the personal biography and family background information of the research samples.

ii. Parental Acceptance-Rejection Questionnaire (PARQ) (Rohner, 2004).

Parental Acceptance-Rejection Questionnaire is a self-report instrument designed to measure an individual's perceptions of parental acceptancerejection. Parental acceptance-rejection is bipolar in dimension, with acceptance defining one end of the continuum and parental rejection defining the other. It measures the individual's perceptions of the warmth, affection, care, nurturance, support or simply love (i.e., parental acceptance) or rejection received in the family of origin. PARQ consists of four scales whereby parental rejection may be expressed in any combination of the four scales including coldness/lack of affection, hostility/aggression, indifference/neglect, and undifferentiated rejection. There are a total of 60 items on a 4-point Likert-type scale in which 4 signifies almost always true and 1 signifies almost never true. The higher the score on any scale or on the total PARQ score, the greater is the perceived parental coldness/lack of affection, hostility/aggression, indifference/neglect, undifferentiated rejection and overall perceived rejection.

This instrument has been selected for use in this study as it has a special version solely for adolescents who are the target group, to measure how they feel as it affects their emotional growth. PARQ is the most reliable family-related self-report instrument in use today. This is because PARQ was constructed to be used cross-culturally as well as for international research. Hence, it is suitable to be used for studying Malaysian adolescents with multi-ethnic backgrounds.

The results of this research help to explain why children's reports of parental acceptance-rejection usually tend to be better predictors of developmental outcomes than do parents' reports. Hence, greater emphasis is placed on the children's perceptions of parental acceptance-rejection than on the parents' perceptions especially if there is a significant discrepancy between children's reports and parents' reports. In addition, parents are often genuinely unaware of small behaviors that are perceived by children to be less than loving. The discrepancy between parents' reports and children's reports is due largely to the fact that parents want to believe they are doing a good job of raising their children. This wish or desire appears to induce some parents to under-report the amount of psychological hurt (i.e., rejection) they impose on their children.

\subsection{Data Collection}

Subsequent consensus was sought from the Department of Planning and Research of the Education Policy Division in the Ministry of Education Malaysia. Upon receiving the approval letter from the Ministry, subsequent permission was sought from the Selangor State Education Department, Shah Alam to conduct the study in the Selangor schools. Thereafter, appointments were made with the school principal of Sekolah Menengah Kebangsaan Seksyen 3 Bandar Kinrara for permission to conduct pilot study and permission was sought from the principals of the other two nearby schools namely Sekolah Menengah Kebangsaan Seksyen 1 Bandar Kinrara and Sekolah Menengah Kebangsaan Seksyen 4 Bandar Kinrara for actual study data collection. Data collection was conducted at the two government secondary schools with the help of four teachers. A briefing on the nature of the study was provided before administering the questionnaires to students. Furthermore, difficult questions were explained to students. Adequate time was provided for them to complete the questionnaires. All of the completed questionnaires were collected back from the samples on the same day.

\subsection{Research Sample Demography Information Data}

This part provides the personal biography and family background information of the research samples. Research samples' personal profile includes the students' name, contact numbers, school, class, gender, ethnic group and academic achievement of 2006 "Penilaian Menengah Rendah" (PMR) examination result. Information on family profile such as parents' education qualifications, parents working status and monthly total household incomes were required for this study.

The PMR Examination is a compulsory public examination for all the students in Form Three. The results of this examination will determine whether students will qualify to study in the Science or Arts Stream when they proceed to Form Four. For the purpose of this study, it was decided to use the students' overall PMR Examination achievement based on the seven compulsory subjects, namely, Bahasa Malaysia, English, Mathematics, Science, History, Geography 
and Moral Education. This data will be a measure of the students' academic achievement.

\subsection{Data Analysis}

The Statistical Package for the Social Sciences (SPSS) version 12.5 was used to analyze data obtained. Both descriptive and inferential statistics were utilized for data analysis. Descriptive statistics in the form of frequency, percentage, mode and mean were used. As for inferential statistics, both independent $t$-test and one way analysis of variance (ANOVA) were conducted.

\section{Results}

7.1. Malaysian Secondary School Students' Perception on Father-Adolescent and MotherAdolescent Relationship with respect to Parental Acceptance-Rejection.

Based on the descriptive statistical analysis (Table 1), the mean score of the overall sample of ParentAdolescent Acceptance-Rejection (PAR) for fatheradolescent relationship was $176.64(S D=22.69)$. As for mother-adolescent relationship, the mean score of the overall sample was $176.24(S D=23.21)$.

Table 1. Father-Adolescent and MotherAdolescent Relationship with respect to Parental Acceptance-Rejection (PAR) Level of Acceptance-Rejection for Overall Sample ( $N=$ 321)

\section{Level of} Perception of Overall Sample on:

Acceptance-

Rejection

\begin{tabular}{lll}
\cline { 2 - 3 } & Father & Mother \\
\hline $\begin{array}{l}\text { 1. More } \\
\text { acceptance than } \\
\text { rejection }\end{array}$ & $44(13.7 \%)$ & $41(12.8 \%)$ \\
& &
\end{tabular}

\section{More rejection $277(86.3 \%) \quad 280(87.2 \%)$}

than acceptance

It was found that the overall sample shared almost the same perception and experience for both their father and mother pertaining to parent-adolescent relationship in parental acceptance-rejection. Both of the male and female students felt more rejection than acceptance from their parents. A total of 277 (86.3\%) students felt more rejection from their fatheradolescent relationship whereby 280 (87.2\%) students felt more rejection from their mother-adolescent relationship. In contrast, $44(13.7 \%)$ students reported that they felt more acceptance from the fatheradolescent relationship and 41 students (12.8\%) felt more acceptance from the mother-adolescent relationship.

\subsection{Comparison of PAR Score between Genders.}

Comparison was made using $t$-test analysis to determine if there is any significant difference in the perception of parent-adolescent relationship with respect to parental acceptance-rejection among male and female students. The results show that there was no significant difference on father-adolescent relationship, $t(319)=-1.85, p>.05$ between male $(M$ $=172.27, S D=21.88)$ and female $(M=176.93, S D=$ 23.28) students. For mother-adolescent relationship, no significant difference was found between male $(M=$ 174.82, $S D=21.72)$ and female $(M=177.61, S D=$ 24.55) students, $t(319)=-1.08, p>.05$.

\subsection{Comparison of PAR Score between Ethnic Groups.}

Malaysia is a multicultural society comprising three main races. In order to study the reality of its secondary school student, hence, different ethnic groups of student have been included in the study. One-way analysis of variance (ANOVA) was conducted to examine PAR among students with different ethnicity included Malay, Chinese, Indian and others. Results (in Table 2) demonstrated that Indian students scored highest on father-adolescent relationship ( $M=185.24)$, followed by other ethnic groups $(M=176.18)$, then by Malay students $(M=$ 173.74) and the lowest was Chinese students $(M=$ 171.43). Based on Table 2, there was a significant difference in father-adolescent relationship between different ethnic groups, $F(3,317)=5.35, p=.00$.

Table 2. One-way Analysis of Variance for Father-Adolescent Relationship with respect to Parental Acceptance-Rejection (PAR) between Ethnic Groups

\begin{tabular}{llllll}
\hline Source & $\begin{array}{l}\text { Sum of } \\
\text { Squares }\end{array}$ & df & $\begin{array}{l}\text { Mean } \\
\text { square }\end{array}$ & $F$ & $p$ \\
\hline $\begin{array}{l}\text { Between } \\
\text { Groups }\end{array}$ & 7937.49 & 3 & 2645.83 & 5.35 & $.00^{\star}$ \\
Within & 156752.86 & 317 & 494.49 & & \\
Groups & & & & & \\
Total & 164690.36 & 320 & & & \\
\hline${ }^{*} p<.05$ & & & & &
\end{tabular}

In terms of mother-adolescent relationship, Indian students displayed the highest score $(M=185.44)$, followed by other ethnic groups $(M=182.27)$, Malay students $(M=176.30)$ and lowest by Chinese students ( $M=172.65)$. Results revealed there was a significant difference in mother-adolescent relationship between 
different ethnic groups, $F(3,317)=4.58, p=.00$ (refer to Table 3).

Table 3. One-way Analysis of Variance for Mother-Adolescent Relationship with respect to Parental Acceptance-Rejection (PAR) between Ethnic Groups

\begin{tabular}{llllll}
\hline Source & $\begin{array}{l}\text { Sum of } \\
\text { Squares }\end{array}$ & $\mathrm{df}$ & $\begin{array}{l}\text { Mean } \\
\text { square }\end{array}$ & $F$ & $p$ \\
\hline $\begin{array}{l}\text { Between } \\
\text { Groups }\end{array}$ & 7124.64 & 3 & 2374.88 & 4.58 & $00^{*}$ \\
Within & 165221.89 & 317 & 521.21 & & \\
Groups & & & & & \\
Total & 172346.53 & 320 & & & \\
\hline${ }^{*} p<.05$ & & & & &
\end{tabular}

\subsection{Comparison of PAR Score by Academic Achievement}

Based on students' academic achievements, 185 students were at the excellent level of academic achievement, 42 students with good achievement, 67 with average achievement and 27 with poor achievement. Generally, students with excellent academic achievement $(M=177.81)$ reported the highest PAR mean score, followed by students with good academic achievement $(M=176.17)$, students with average achievement $(M=169.09)$ and students with poor academic achievement $(M=164.30)$. There was a significant difference for father-adolescent relationship across students with different academic achievements, $F(3,317)=4.62, p=.00$.

Table 4. One-way Analysis of Variance for Father-Adolescent Relationship with respect to Parental Acceptance-Rejection (PAR) According to Academic Achievement

\begin{tabular}{llllll}
\hline Source & $\begin{array}{l}\text { Sum of } \\
\text { Squares }\end{array}$ & df & $\begin{array}{l}\text { Mean } \\
\text { square }\end{array}$ & $F$ & $p$ \\
\hline Between & 6904.44 & 3 & 2301.48 & 4.62 & $.00^{\star}$ \\
Groups & & & & & \\
Within & 157785.92 & 317 & 497.75 & & \\
Groups & & & & & \\
\hline Total & 164690.36 & 320 & & & \\
\hline${ }^{\star} p<.05$ & & & &
\end{tabular}

Students with excellent academic achievement $(M$ $=180.22$ ) reported the highest PAR mean score in terms of mother-adolescent relationship, followed by students with good achievement $(M=177.31)$, students with average achievement $(M=170.24)$ and students with poor achievement $(M=162.22)$. According to Table 4, result indicated that there was a significant difference for mother-adolescent relationship across students with different academic achievements, $F$ (3, 317) $=6.99, p=.00$.
Table 5 One-way Analysis of Variance for Mother-Adolescent Relationship with respect to Parental Acceptance-Rejection (PAR) between Academic Achievement Levels

\begin{tabular}{llllll}
\hline Source & $\begin{array}{l}\text { Sum of } \\
\text { Squares }\end{array}$ & df & $\begin{array}{l}\text { Mean } \\
\text { square }\end{array}$ & $F$ & $p$ \\
\hline $\begin{array}{l}\text { Between } \\
\text { Groups }\end{array}$ & 10691.36 & 3 & 3563.79 & 6.99 & $.00^{*}$ \\
Within & 161655.17 & 317 & 509.95 & & \\
Groups & & & & & \\
Total & 172346.53 & 320 & & & \\
\hline${ }^{*} p<.05$ & & & & &
\end{tabular}

\subsection{Comparison of PAR Score between Father and Mother Education Qualifications}

Based on the data obtained, there were 31 fathers without any formal education/with primary education, 161 fathers having lower/upper secondary school education and 129 fathers having college/university level education. In terms of mothers' education, 43 mothers had not received formal education/had completed primary education, 186 mothers had lower/upper secondary education and 92 mothers had completed college/university education.

There was no significant difference for fatheradolescent relationship with respect to parental acceptance-rejection across fathers with various levels of education qualifications, $F(2,318)=2.21, p>.05$. Furthermore, there was no significant difference for father-adolescent relationship across mothers with different education qualification, $F(2,318)=1.30$, $p>.05$.

As for mother-adolescent relationship with respect to parental acceptance-rejection, results revealed no significant difference across fathers with different education qualifications, $F(2,318)=2.76, p>.05$. There was no significant difference in motheradolescent communication between mothers of different level of education qualifications, $F(2,318)=$ $1.84, p>.05$.

\subsection{Comparison of PAR Score between Parents' Working Statuses}

There were 141 students with both working parents, 159 students with father working only, 7 students with working mother and 14 students with parents who are not working.

Results showed no significant difference for fatheradolescent relationship with respect to parental acceptance-rejection across different parents' working status, $F(3,317)=.75, p>.05$. Similarly, there was no significant difference for the mother-adolescent 
relationship with respect to parental acceptancerejection across parents with different working status, $F(3,317)=1.70, p>.05$.

\subsection{Comparison of PAR Score between Monthly Total Household Incomes}

There were 64 students from families with monthly total household income in the range of RM 0 - RM 1,000, 110 students from families with monthly income of RM 1,001 - RM 3,000, 84 students with family income of RM 3,001 - RM 5,000 and 63 students with families earning above RM 5,000.

In terms of father-adolescent relationship with respect to parental acceptance-rejection, no significant difference was found between students with different monthly household incomes, $F(3,317)=.17, p>.05$. There was no significant difference for motheradolescent relationship across different level of monthly total household incomes too, $F(3,317)=.50$, $p>.05$.

\section{Discussion}

The findings of the present study demonstrated that the mother-adolescent relationship was found to have higher PAR than the father-adolescent relationship with respect to parental acceptance-rejection. Also, there was no significant difference in PAR found between male and female students for fatheradolescent and mother-adolescent relationship with respect to parental acceptance-rejection.

Students in general were faced with high level of rejection whereby $86.3 \%$ students reported more rejection than acceptance for the father-adolescent relationship and $87.2 \%$ students revealed more rejection than acceptance for the mother-adolescent relationship. This serves as an indicator that students were going through a very challenging stage of life due to the higher level of rejection than acceptance they faced. Hence, this might explain the increased rate of delinquency cases among adolescent in Malaysia.

The findings clearly show that there was significant difference for parent-adolescent relationship with respect to parental acceptance-rejection across different ethnic groups. It explains that student disregard of different ethnic groups were experiencing parental acceptance-rejection in their family life. It implied that parents from different culture and background need to be well informed more on the knowledge of parenting and students need to be taught ways to help themselves.

Results show a significant difference for the parentadolescent relationship with respect to parental acceptance-rejection between students with different academic achievements. Specifically, students with poorer academic achievement reported higher level of rejection than acceptance. This in turn reflects the truth of Malaysian society that is examination oriented. Therefore, students are bound to face situations where their self-worth was measured by their academic achievement.

Nevertheless, there was no significant difference found for the comparisons of PARQ in fatheradolescent and mother-adolescent between other variables namely parent's education qualifications, parents' working status and monthly total household incomes.

\section{Practical Implications}

The basic concern of the study was to investigate the perception of the student on the father and mother relationship with regard to parental acceptancerejection and examine the possible explanation for differences in the personal criteria and family criteria. This information on the students' perceptions of father and mother may be useful to parents, educationists, principals, teachers and counsellors who wish to improve the parent-adolescent relationship in order to maximize the growth of the adolescents and their wellbeing and help efforts in developing more effective and productive parents.

If school counsellors are to design the most appropriate interventions and developmental activities, they must know the concerns and needs of the population they serve. In the case of counselling student related to their parents therefore there is a possibility to undertake family counselling which involves student's parents as well in order to have more effective and efficient counselling to benefit the students as a whole. It is important to conduct counselling assessment exercise on students in order to gain wisdom, understanding and insights into the students' world; this in turn contributes to satisfying the students' requirements and needs.

\section{Recommendations for Future Research}

This present research can be described as an exploratory study. Based on the findings and conclusions of this study, the following areas for further research are recommended.

Future research might continue to examine the variables which measure the parent-adolescent relationship with regard to parental acceptancerejection and its impact on adolescent growth.

More data could be collected from a national random sample to help parents, principals, 
educationists, teachers and counsellors understand adolescent in a clearer perspective.

The study could be replicated to introduce samples comprising students of selected ethnic group so that a thorough study also can be examined.

This was a cross-sectional research; thus, it is recommended that students' perception of parentadolescent relationship with regard to parental acceptance-rejection be studied over a longitudinal investigation.

The study could be extended longitudinally to the same group of students in their years of secondary schooling except in the year of public examination to see whether their perceptions of parent-adolescent relationship with regard to parental acceptancerejection are consistent at different levels or whether they will change with age.

Samples of the study are limited to the Malaysian students in the urban secondary school. In view of this fact the results obtained and the conclusions drawn in this study are not generalizable to the population at large. Hence, studies should be conducted to include secondary school students from various parts of the country

The quality of the parent-adolescent relationship with regard to parental acceptance-rejection might differ in different stages of the family life cycle; it is possible that the findings arising from families in the present study (families with adolescent children) might not be generalizable to families in other stages of the family life cycle. Therefore, further studies using samples in other stages of the family life cycle should be conducted.

\section{Limitations}

Despite several significant findings generated from the present study, a number of limitations are observable. First, the samples were recruited only from urban residential areas and hence the generalizability of the current findings to other students located in suburban areas was limited. Also, sample size used for the present study was comparatively small and limited to only two schools from a homogenous background which is mainly middle class. Thus, findings from this school based study might only be generalized to schools having similar characteristics as the study sample.

The examination of parent-adolescent relationship with respect to parental acceptancerejection was measured by six major variables from both students' personal and family criteria. As such, the limited number of variables might overlook the identification of other variables which might be significant contributors to the variance. For instance, parent-adolescent personal characteristics might be another variable to be further explored.

Lastly, the recruited sample was found to be not evenly representing Malaysia's population as it was mainly dominated by Chinese students. Therefore, the present findings might represent the Chinese group's background and culture rather than reflecting the actual composition of the Malaysian adolescent population.

\section{Conclusion}

Despite its limitations this study serves as a preliminary indicator of the future needs of students who are in the stage of preparing themselves to become mature adults. Generally, the majority of students reported higher level of rejection than acceptance in the parent-adolescent relationship.

Specifically, it was found that ethnicity and students' academic achievement had significant impact on the parent-adolescent relationship with respect to parental acceptance-rejection. Hence, future research should be conducted to strengthen the knowledge base of current findings as well as to further explore other variables which might contribute to enhancing the parent-adolescent relationship in order to increase the level of parental acceptance which is crucial for adolescents' total development.

\section{References}

[1] Nielsen, L. (1996). Adolescence: A contemporary view. Belmont, CA: Wadsworth/Thomson Learning.

[2] Papalia, D. E. (2001). Human development. New York, NY: McGraw Hill.

[3] Grinder, R. E. (1978). Adolescence. New York, NY: Wiley.

[4] Roharty Mohd. Majzub. (1989). Sources of adolescent parental conflict according to the perception of adolescents. Malaysian Journal of Family Studies. Kuala Lumpur: Utusan Printcorp Sdn Bhd.

[5] Glasser, W. (1998) Choice theory: A new psychology of personal freedom. New York HarperCollins.

[6] Dacey, J., \& Keeny, M. (1997). Adolescent development. New York: McGraw-Hill.

[7] Chiam, H. K. (1994) Bringing up children in troubled times. Petaling Jaya: Pelanduk Publication.

[8] Trojanowicz, R. C., \& Morash, M. (1992). Juvenile delinquency: Concepts and control. Englewood Cliffs, NJ: Prentice Hall. 
[9] Keefauver, L. (1996). Lord, I wish my teenager would talk with me. USA: Laurence House Strang Communication Company.

[10] Rohner, R. P., \& Rohner, E. C. (1981). Parental acceptance-rejection and parental control: Cross-cultural codes. Ethnology, 20, 245-260.

[11] Rohner, R. P. (1975). They love me, they love me not: A worldwide study of the effects of parental acceptance and rejection. USA: HRAF Press.

[12] Abdullah Malim Baginda. (1984). Juvenile delinquency and some measures to control its increasing trends. ERIC Document No. ED 273359.

[13] Cross, R. (2002). The effects of an adventure education program on perceptions of alienation and personal control among at-risk adolescents. The Journal of Experiential Education, 25(1), 247-254.

[14] Yap, Y. L. (2000). Hubungan antara penglibatan ibubapa dan status sosioekonomi dengan pencapaian akademik. Universiti Malaya.

[15] Rohner, R. P., \& Pettengill, S. M. (1985). Perceived parental acceptance-rejection and parental control among Korean adolescents. Child Development, 56, 524-528.

[16] Eskilson, A. W., Muehlbauer, M. G., \& Dodder, L. (1986). Parental pressure, self-esteem and adolescent reported deviance: Bending the twig too far. Adolescence, 21, 501-515.

[17] Phares, V., \& Renk, K. (1998). Perceptions of parents: A measure of adolescents' feelings about their parents. Journal of Marriage and the Family, 60, 646-659.

[18] Barnes, G. M., \& Farrel, M. P. (1992). Parental support and control predictors of adolescent drinking, delinquency and related problem behaviors. Journal of Marriage and the Family, 54, 763-776.

[19] Shek, D. T, L. (2000), Differences between fathers and mothers in the treatment of, and relationship with their teenager children: Perception of Chinese adolescents. Adolescence, 35, 137,135-146.

[20] Kerlinger, F. (1973). Foundations of behavioral research. New York: Holt, Rinehart and Winson. 